(2) Open Access Full Text Article

ORIGINAL RESEARCH

\title{
Longitudinal Evaluation of the Relationship Between Low Socioeconomic Status and Incidence of Chronic Obstructive Pulmonary Disease: Korean Genome and Epidemiology Study (KoGES)
}

This article was published in the following Dove Press journal: International Journal of Chronic Obstructive Pulmonary Disease

\author{
Chi Young Kim (iD) 1,2 \\ Beong Ki Kim (1) \\ Yu Jin Kim' \\ Seung Heon Lee (1D) \\ Young Sam Kim $\mathbb{D}^{3}$ \\ Je Hyeong Kim '
}

'Division of Pulmonary, Allergy, and Critical Care Medicine, Department of Internal Medicine, Korea University Ansan Hospital, Ansan, Republic of Korea; ${ }^{2}$ Yonsei University College of Medicine, Seoul, Republic of Korea;

${ }^{3}$ Division of Pulmonology, Department of Internal Medicine, Institute of Chest Diseases, Severance Hospital, Yonsei University College of Medicine, Seoul, Republic of Korea
Correspondence: Je Hyeong Kim Division of Pulmonary, Allergy, and Critical Care Medicine, Department of Internal Medicine, Korea University Ansan Hospital, 123, Jeogguem-ro, Danwon-gu, Ansan-si, Gyeonggi-do 15355, Republic of Korea

Tel +82-3I-4I 2-5950

Fax +82-3I-4I3-5950,

Email chepraxis@korea.ac.kr
Background: Socioeconomic status (SES) is a strong determinant in the development of various diseases. We evaluated the relationship between SES and the incidence of chronic obstructive pulmonary disease (COPD) by using a community-based cohort data.

Patients and Methods: Four-year follow-up data of 6341 adults (aged $\geq 40$ years), who underwent serial pulmonary function test were analyzed. Incidence of COPD in the participants was defined as the absence of airflow obstruction compatible with COPD (pre-bronchodilator forced expiratory volume in 1 second/forced vital capacity ratio of $<0.7$ ) at baseline but documentation of airflow obstruction in serial testing. SES of patients was divided into quartiles according to household income and educational level. Multivariate logistic regression analyses were performed to estimate the association between SES and COPD incidence.

Results: A total of 280 (4.4\%) patients developed COPD during the follow-up. The proportion of subjects with lowest education (elementary school) and lowest household income levels (1st quartile) was significantly higher in the COPD group than in the nonCOPD group ( $37.9 \%$ vs $29.5 \%, \mathrm{p}<0.011$ and $48.4 \%$ vs $30.8 \%, \mathrm{p}<0.001$, respectively). Logistic regression analysis revealed that education level of elementary school was independently associated with COPD incidence after adjustment for sex, age, body mass index, white blood cell count, residence area, and occupation (odds ratio $1.879,95 \%$ confidence interval 1.124-3.141, $\mathrm{p}=0.016)$.

Conclusion: In the general population, educational level of elementary school was an independent risk factor for COPD among the components comprising SES. Our results indicate that the implementation of preventive strategies for COPD in those with low educational status could be beneficial.

Keywords: chronic obstructive pulmonary disease, socioeconomic status, education level, incidence, prevalence

\section{Introduction}

SES (socioeconomic status) is a comprehensive measure, which reflects the individual's economic and social status within a community and is closely related to health. ${ }^{1}$ Various components such as income, education, occupation, location of residence, housing conditions, and participation in social organizations are used to 
define the SES of a person. ${ }^{1}$ Accumulating evidence now indicates that low SES (LSES) could also be related to the respiratory well-being of a person and can contribute to the development of various pulmonary diseases and influence the clinical outcomes of respiratory diseases. ${ }^{2-6}$ The impact of LSES on respiratory health has been attributed to poorer housing conditions, diet, hazardous occupational exposure, and a higher prevalence of smoking and secondhand smoking. ${ }^{3,7-11}$ Meanwhile, it has been also suggested that LSES is associated with the decline of lung function in the general population. ${ }^{12}$

Chronic obstructive pulmonary disease (COPD) is a disease defined by the presence of persistent airflow limitation, which is strongly associated with smoking. ${ }^{13-15}$ COPD usually affects people over the age of 40 years and is one of the leading causes of death globally. Given that COPD is characterized by decreased lung function and LSES has been shown to negatively impact pulmonary function, previous studies have focused on elucidating the relationship between LSES and COPD. Wijnhoven and Hesselink et al have revealed that LSES is an important risk factor for lower health-related quality of life in COPD patients. ${ }^{16,17}$ Moreover, it has been also suggested that LSES is closely linked to a higher prevalence of COPD. ${ }^{18-22}$

Nevertheless, as previous studies used a cross-sectional design to determine the relationship between LSES and the prevalence of COPD, ${ }^{23-26}$ it is still unclear whether LSES is associated with the incidence of COPD. Therefore, the purpose of this study was to evaluate the association between LSES and the incidence of COPD using longitudinal data derived from a large-scale community-based cohort.

\section{Patients and Methods}

\section{Study Population}

We used the data from the Ansung-Ansan cohort study, which was initiated in 2001 and supported by the National Genome Research Institute of Korea Centers for Disease Control and Prevention. This study is a part of the Korean Genome and Epidemiology Study (KoGES) that is based on a series of large community-based epidemiological surveys investigating chronic diseases in South Korea. ${ }^{27}$ The Ansung-Ansan cohort, which has been described in previous studies, ${ }^{28,29}$ enrolled participants aged 40-69 years from both the urban (Ansan) and rural (Ansung) areas of South Korea for prospective investigation and collection of clinical information. During the baseline health examination from June 18, 2001, to January 29, 2003, 5012 participants from Ansan and 5018 from Ansung visited the Korea University Ansan Hospital and the Ajou University Medical Center, respectively. Only data of those participants who underwent pulmonary function test at baseline and had undergone follow-up testing at the second and fourth year were analyzed. The flowchart for patient inclusion and exclusion is presented as Figure 1.

\section{Patient Data, Classification of Socioeconomic Status, and Definition of Airflow Obstruction for COPD}

The collected patient data included age, sex, residence area, body mass index (BMI), presence of comorbid condition of hypertension and diabetes mellitus. Laboratory data of white blood cell (WBC) count and C-reactive protein, as well as smoking status and the amount of smoking (assessed as pack-year) was also estimated.

The SES of a participant was defined according to the household income and educational level. The household income of every participant was classified into quartiles based on the average monthly incomes, and the education level was also categorized into four groups by the final education level: 1st, elementary school; 2nd, middle school; 3rd, high school; and 4th, college which included university.

Pulmonary function test was performed by a skilled technician using a standard spirometer (Vmax-2130, Sensor Medics, Yorba Linda, CA, USA). Calibration and quality control of spirometry examinations were performed regularly based on American Thoracic Society guidelines. ${ }^{30}$ The diagnostic cut-off for airflow obstruction compatible with COPD was a pre-bronchodilator forced expiratory volume in 1 second (FEV1) to forced vital capacity (FVC) ratio of less than 0.7 .

\section{Statistical Analysis}

We used R 3.3.6 (R Foundation for statistical computing) to perform all statistical analyses. All values were expressed as mean \pm standard deviation (SD). Continuous and categorical variables were compared using Student's $t$-test and the chi-square test, respectively. Univariate and multivariate logistic regression analyses were performed to estimate the odds ratio (OR) with a $95 \%$ confidence interval (CI) for the incidence of 


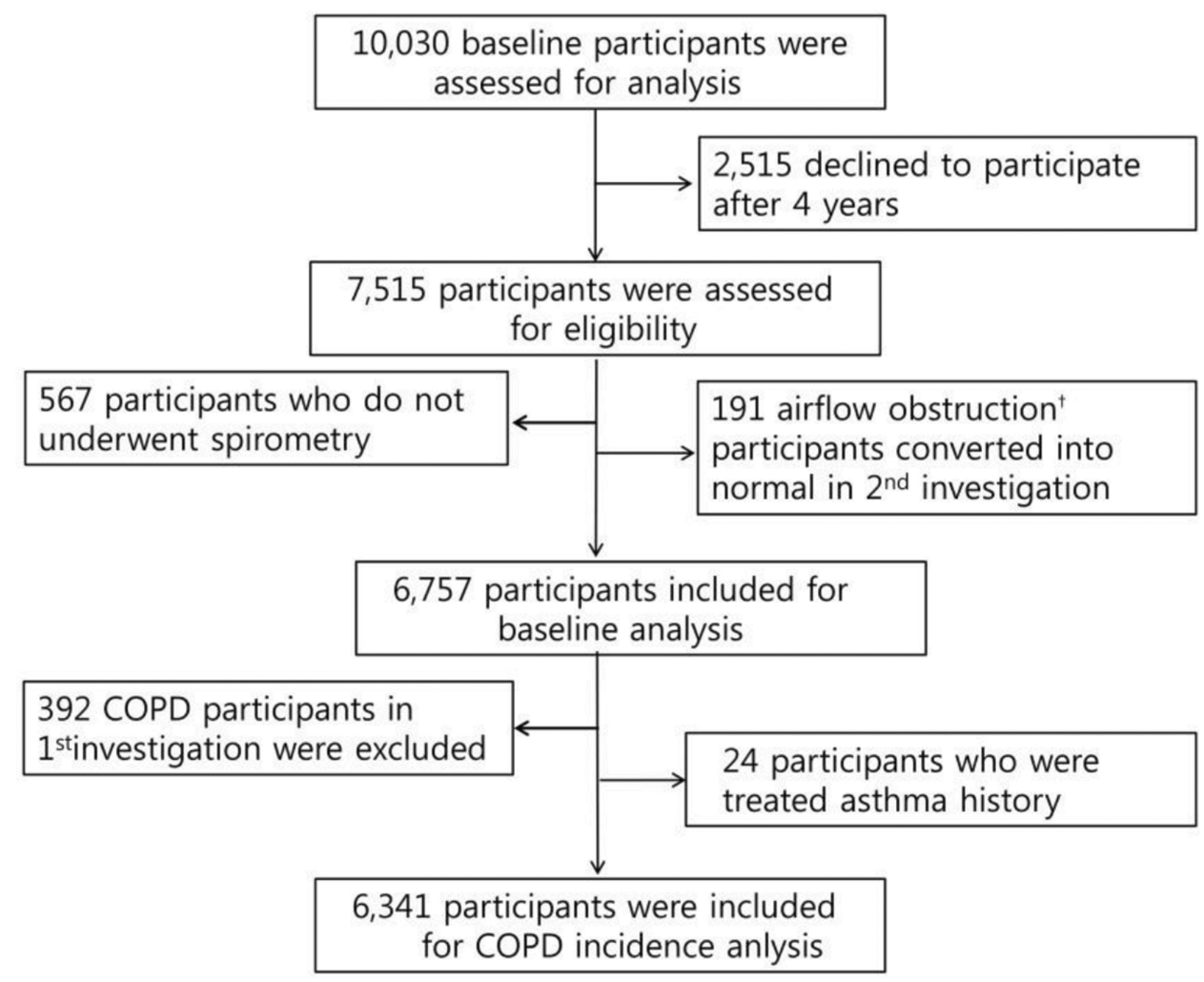

Figure I Study population and design.

Notes: ${ }^{\dagger}$ Airflow obstruction: forced expiratory volume in I second/forced vital capacity ratio < 0.7 .

Abbreviation: COPD, chronic obstructive pulmonary disease.

COPD. $\mathrm{P}<0.05$ was considered to be statistically significant in all analyses.

\section{Ethical Approval}

The Korean Centers for Disease Control and Prevention obtained written informed consent from all participants, and the Institutional Review Board of Korea University Ansan Hospital approved the protocol (IRB Number 2019AS0102) of this study.

\section{Results}

\section{The Incidence of COPD and Baseline Characteristics of the Subjects}

The prevalence of COPD was found to be $5.8 \%$ at baseline (392/6757), and during the follow-up of 4 years, 280 subjects (4.4\%) were newly diagnosed as having COPD. The baseline characteristics of 6341 participants are shown in Table 1. Subjects who developed COPD were older and a higher proportion of them were men than women compared to those in the non-COPD group (mean age 57.0 vs 51.0 and proportion of men $81.1 \%$ vs $44.7 \%$, all $\mathrm{p}<0.001$ ).
Those in the COPD group had significantly lower BMI and mean predicted values of $\mathrm{FEV}_{1}, \mathrm{FVC}$, and $\mathrm{FEV}_{1} / \mathrm{FVC}$ than those in the non-COPD group (all $\mathrm{p}<0.001$ ). Additionally, the proportion of ex-smokers and current smokers and the amount of smoking (pack-year) were significantly higher in the COPD group than in the nonCOPD group (all $\mathrm{p}<0.001$ ). Compared to that in the nonCOPD group, the WBC count was also significantly higher in the COPD group $(\mathrm{p}=0.005)$.

\section{Socioeconomic Status in the COPD and Non-COPD Group}

The details of SES in the COPD and non-COPD groups are also presented in Table 1. A significant difference was found in household income and education level between the COPD and non-COPD groups $(p<0.001$ and $p=0.011)$. The proportion of participants in the 1st quartile of income was higher in the COPD group than that in the non-COPD group ( $48.4 \%$ vs $30.8 \%, \mathrm{p}<0.001)$. Regarding education level, the proportion of participants with elementary school education was higher in the COPD group than that in the non-COPD group $(37.9 \%$ vs $29.5 \%, \mathrm{p}<0.001)$. 
Table I Comparison of Characteristics Between the COPD and Non-COPD Groups

\begin{tabular}{|c|c|c|c|c|}
\hline & COPD $(n=280)$ & Non-COPD $(n=6061)$ & Total $(n=634 I)$ & p-value \\
\hline Age, years & $57.0 \pm 8.7$ & $51.0 \pm 8.4$ & $51.3 \pm 8.5$ & $<0.001$ \\
\hline Male sex, N (\%) & $227(8 \mathrm{I} .1)$ & $2710(44.7)$ & $2937(46.3)$ & $<0.001$ \\
\hline Residence area & & & & $<0.001$ \\
\hline Rural & $2929(48.3)$ & $185(66.1)$ & $3131(49.1)$ & \\
\hline Urban & $3132(51.6)$ & 95 (33.9) & $3227(50.9)$ & \\
\hline Body mass index, $\mathrm{kg} / \mathrm{m}^{2}$ & $23.6 \pm 2.7$ & $24.7 \pm 3.0$ & $24.7 \pm 3.0$ & $<0.001$ \\
\hline $\mathrm{FEV}_{1}, \%$ predicted & $105.1 \pm 16.7$ & $114.5 \pm 16.1$ & $114.1 \pm 16.3$ & $<0.001$ \\
\hline FVC, \% predicted & $104.1 \pm 15.8$ & $105.2 \pm 14.2$ & $105.1 \pm 14.3$ & $<0.001$ \\
\hline FEVI/FVC & $73.9 \pm 4.2$ & $81.8 \pm 5.3$ & $81.5 \pm 5.5$ & $<0.001$ \\
\hline Hypertension, N (\%) & $89(31.8)$ & $|77|(29.2)$ & $1860(29.3)$ & 0.393 \\
\hline Diabetes mellitus, N (\%) & $26(9.3)$ & $587(9.7)$ & $613(9.7)$ & 0.906 \\
\hline White blood cell count, $10^{3} / \mathrm{uL}$ & $6.9 \pm 1.8$ & $6.5 \pm 1.8$ & $6.5 \pm 1.8$ & 0.005 \\
\hline C-reactive protein, $\mathrm{mg} / \mathrm{dL}$ & $0.2 \pm 0.3$ & $0.2 \pm 0.5$ & $0.2 \pm 0.5$ & 0.878 \\
\hline Smoking status, N (\%) & & & & $<0.001$ \\
\hline Never smoker & $63(23.6)$ & $3777(63.0)$ & $3840(61.2)$ & \\
\hline Ex-smoker & $74(26.5)$ & $938(15.6)$ & $1012(16.1)$ & \\
\hline Current smoker & $142(50.9)$ & $1285(2 \mid .4)$ & $1423(22.7)$ & \\
\hline Smoking, pack-year & $20.2 \pm 19.4$ & $7.4 \pm 13.7$ & $8.0 \pm 14.3$ & $<0.001$ \\
\hline Household income quartile, N (\%) & & & & $<0.001$ \\
\hline Ist & $134(48.4)$ & $1836(30.8)$ & $1979(31.6)$ & \\
\hline 2nd & $75(27.1)$ & $1804(30.3)$ & $1879(30.1)$ & \\
\hline $3 r d$ & 55 (19.9) & $|82|(30.6)$ & $1876(30.1)$ & \\
\hline 4 th & $13(4.7)$ & $497(8.3)$ & $510(8.2)$ & \\
\hline Education level, $\mathrm{N}(\%)$ & & & & 0.011 \\
\hline Elementary school & $106(37.9)$ & $1775(29.5)$ & I88I (29.8) & \\
\hline Middle school & $66(23.6)$ & $1375(22.8)$ & $|44|(22.8)$ & \\
\hline High school & $73(26.1)$ & $1965(32.6)$ & $2038(32.3)$ & \\
\hline College & $35(12.4)$ & $912(15.1)$ & $947(I 5.0)$ & \\
\hline
\end{tabular}

Note: Data are presented as mean \pm standard deviation or $\mathrm{N}(\%)$.

Abbreviations: COPD, chronic obstructive pulmonary disorder; FEVI, forced expiratory volume in I second; FVC, forced vital capacity.

\section{The Influence of SES on the Incidence of COPD}

Univariate analysis revealed that age, sex, BMI, smoking (pack-year), WBC count, and lower income and education status, occupation of farmer, and the residence of rural area were associated with the incidence of COPD (Table 2). However, in a multivariate analysis, it was shown that the development of COPD was independently associated with elementary school education (odds ratio $[\mathrm{OR}]=1.879,95 \%$ confidence interval [CI] 1.124-3.141, $\mathrm{p}=0.016$ ) (Table 3).

\section{Discussion}

In this study, we found that individuals who developed COPD had lower household income and low educational level at baseline compared to those without COPD.
Interestingly, even after adjusting for conventional risk factors of COPD including age, male sex, smoking, occupation, and residence area ${ }^{31}$ it was identified that lower educational level (elementary school) was an independent risk factor for the incidence of COPD. To the best of our knowledge, this is the first study to evaluate the temporal relationship between LSES and the development of COPD. Furthermore, the data were derived from a large, prospective community-based general population, and the identification of COPD was objectively assessed using results of repeated pulmonary function tests.

Although there are data suggesting LSES is associated with the deterioration of pulmonary function, inconsistent results that linked LSES to COPD were found which is the most relevant components of LSES that is linked to 
Table 2 Univariate Logistic Regression Analysis for COPD Incidence During Follow-Up

\begin{tabular}{|l|l|l|l|}
\hline & $\begin{array}{l}\text { Odds } \\
\text { Ratio }\end{array}$ & $\begin{array}{l}\text { 95\% Confidence } \\
\text { Interval }\end{array}$ & p-value \\
\hline Age & 1.081 & $1.066-1.096$ & $<0.001$ \\
Male sex & 5.296 & $3.911-7.172$ & $<0.001$ \\
Body mass index & 0.872 & $0.830-0.917$ & $<0.001$ \\
Hypertension & 1.129 & $0.872-1.460$ & 0.357 \\
Diabetes mellitus & 0.825 & $0.632-1.442$ & 0.955 \\
Smoking, pack-year & 1.039 & $1.033-1.045$ & $<0.001$ \\
White blood cell count & 1.093 & $1.028-1.163$ & 0.005 \\
Lower household & 1.957 & $1.48 I-2.588$ & $<0.001$ \\
income quartile & & & \\
Lower education status & 1.455 & $1.137-1.860$ & 0.003 \\
Occupation, farmer & 2.444 & $1.916-3.119$ & $<0.001$ \\
Residence of rural area & 2.082 & $1.618-2.680$ & $<0.001$ \\
\hline
\end{tabular}

Abbreviation: COPD, chronic obstructive pulmonary disorder.

Table 3 Multivariate Logistic Regression Analysis of COPD Development During Follow-Up

\begin{tabular}{|l|l|l|l|}
\hline & $\begin{array}{l}\text { Odds } \\
\text { Ratio }\end{array}$ & $\begin{array}{l}\text { 95\% Confidence } \\
\text { Interval }\end{array}$ & p-value \\
\hline $\begin{array}{l}\text { Income, quartile } \\
\text { Ist quartile }\end{array}$ & 1.044 & $0.507-2.150$ & 0.908 \\
2nd quartile & 0.901 & $0.457-1.776$ & 0.763 \\
3rd quartile & 0.988 & $0.512-1.907$ & 0.971 \\
4th quartile & Reference & & \\
\hline Education level & & & \\
Elementary school & 1.879 & $1.124-3.141$ & 0.016 \\
Middle school & 1.143 & $0.702-1.862$ & 0.591 \\
High school & 1.469 & $0.883-2.442$ & 0.138 \\
College & Reference & & \\
\hline
\end{tabular}

Note: The data are adjusted by age, sex, body mass index, smoking (pack-year), white blood cell count, occupation, and residence.

Abbreviation: COPD, chronic obstructive pulmonary disorder.

COPD. ${ }^{32-34}$ Chen et al reported that lower income was related to the prevalence of COPD, ${ }^{35}$ whereas Steenland et al reported education level, but not income, was associated with COPD. ${ }^{33}$ A possible explanation for the discordant results is that the definition of SES is largely variable, which could be affected by multiple confounding factors such as smoking status, occupation, prenatal exposure, air pollution, housing conditions, environmental exposure, and the wealth of the social community. 7,9

A previous study showed that LSES based on education and household income is associated with asthma and COPD prevalence in the adult population. ${ }^{26}$ Similarly, we also found that subjects who developed COPD had lower household income and educational level at the time of study inclusion. Even though the direct relationship between LSES and COPD is unclear, it could be possibly related to the fact that LSES is generally related to poor healthcare access, which could lead to advanced lung disease. ${ }^{36}$ However, the advantage of this study compared to the publication by Kanervisto et al is that smoking was more precisely categorized including amount of smoking (pack-years) and the diagnosis of COPD was established objectively based on the results of pulmonary function test. Finally, in the present study, we found that the development of COPD was independently related to lower education level.

SES is a multidimensional concept consisting of educational level, income, and occupational status. ${ }^{37}$ Findings of the present study demonstrated that self-reported occupation of farmer was more common in participants with COPD (Table 4). This is consistent with the result of a previous study, which showed that farmers have a higher prevalence of COPD, and supports the hypothesis that there is a relationship between occupational exposure in agriculture and the development of COPD. ${ }^{37}$ However,

Table 4 Other SES Factors According to the Incidence of COPD

\begin{tabular}{|c|c|c|c|c|}
\hline & $\begin{array}{l}\text { COPD } \\
(\mathrm{N}=\mathbf{2 8 0})\end{array}$ & $\begin{array}{l}\text { Non-COPD } \\
(\mathrm{N}=6061)\end{array}$ & $\begin{array}{l}\text { Total } \\
(\mathrm{N}=6341)\end{array}$ & p-value \\
\hline Occupation, N (\%) & & & & $<0.001$ \\
\hline Housewife & $26(9.3)$ & $179 \mid(29.6)$ & $1817(28.7)$ & \\
\hline Office job & $12(4.3)$ & $288(4.8)$ & $300(4.73)$ & \\
\hline Farm workers & $125(44.6)$ & $1520(25.1)$ & $1645(26.0)$ & \\
\hline Self-employed & $34(12.1)$ & $922(15.2)$ & $956(15.1)$ & \\
\hline Salesman & $0(0)$ & $88(1.5)$ & $88(1.39)$ & \\
\hline Production worker & $14(5.0)$ & $358(5.9)$ & $372(5.9)$ & \\
\hline Professions & $14(5.0)$ & $257(4.2)$ & $271(4.3)$ & \\
\hline Others & $52(18.6)$ & $814(13.4)$ & $866(13.7)$ & \\
\hline House, N (\%) & & & & 0.313 \\
\hline None & I (0.4) & $53(0.9)$ & $54(0.8)$ & \\
\hline Private & $246(86.8)$ & $5061(83.5)$ & $5304(83.6)$ & \\
\hline Charter monthly rent & $30(10.7)$ & $817(13.5)$ & 854 (13.4) & \\
\hline Others & $6(2.1)$ & $100(1.6)$ & $106(1.7)$ & \\
\hline Insurance, N (\%) & & & & 0.160 \\
\hline None & I $(0.4)$ & $39(0.6)$ & $40(0.6)$ & \\
\hline National insurance & $248(88.6)$ & 5571 (91.9) & $5819(91.8)$ & \\
\hline Medical care & $30(10.7)$ & $429(7.1)$ & $459(7.2)$ & \\
\hline $\begin{array}{l}\text { Medical expenditure } \\
\text { quartile/month, } N(\%)\end{array}$ & & & & 0.770 \\
\hline Ist & $77(27.5)$ & $158 \mid(26.1)$ & $1658(26.1)$ & \\
\hline 2nd & $124(44.3)$ & $2743(45.3)$ & 2867 (45.2) & \\
\hline $3 r d$ & $44(15.7)$ & $1088(18.0)$ & 1132 (17.9) & \\
\hline 4th & $33(11.8)$ & $610(10.1)$ & $643(10.1)$ & \\
\hline
\end{tabular}

Abbreviations: SES, socioeconomic status; COPD, chronic obstructive pulmonary disorder. 
in a logistic regression analysis, it was found that LSES, not farming, was a predictor of COPD. Although it is known that higher occupational exposure to air pollution may be considered a potential confounding factor linking LSES to COPD, the American Thoracic Society and the European Respiratory Society guidelines emphasize that current SES is a risk factor for COPD, along with other known factors such as smoking, environmental pollution, and occupational exposure to dust or gas. ${ }^{38}$ However, considering that we were not able to include the potential confounding effects of these factors on COPD, it should be further verified whether LSES is associated with the incidence of COPD.

We found that the incidence of COPD was associated with lower educational level but not with lower household income. Although the exact reason for this discrepancy is unclear, the non-significant association between household income and SES could be partly attributed to the fact that the definition of household income was relatively determined. Meanwhile, two hypotheses can be made regarding the role of lower education level in the incidence of COPD. First, smoking is a major risk factor for the development of COPD and was found to be more frequent among subjects with LSES. ${ }^{39}$ However, because lower education level was independently associated with COPD, it is possible that distinct mechanisms could link lower education level to the incidence of COPD. Second, the lower educational level may be related to the occurrence of COPD as a consequence of the difference in occupational and residential types. ${ }^{40,41}$

Based on the findings from this study, it could be suggested that implementation of measures to raise awareness of COPD especially in those with low educational status can be helpful to prevent the development of COPD. First, as smoking and second-hand smoking are important contributors in the development of COPD, it is necessary to provide educational strategies to avoid smoking to prevent the gradual decrease of pulmonary function. Of note, a previous mendelian randomization study revealed that higher education leads to a reduced likelihood of smoking and greater likelihood of smoking cessation among smokers. ${ }^{42}$ In addition, on evaluating the impact of the area of residence (rural or urban) on COPD with SES, we found a higher incidence of COPD (Table 1) and number of participants with lower SES in rural areas than in urban areas (Table S1). Given that subjects in the COPD group more often resided in the rural area and practiced farming, it may be emphasized that the decrease in exposure to occupational and living dusts could help avoid the deterioration in pulmonary function.

There are several limitations present in this study. First, we could not evaluate the effect of other potential confounders of COPD, such as air pollution and comorbidities; only hypertension and diabetes mellitus were included. Second, the criteria for diagnosis and management of COPD have changed over the last decades. Application of the diagnostic cut-off for airflow obstruction compatible with COPD as pre-bronchodilator FEV1/ FVC $<0.7$ could have influenced the interpretation of study results. ${ }^{42}$ Third, even though it was found that low educational status was associated with the incidence of COPD, the direct causal relationship could not be elucidated in this study. Additional studies involving a larger number of participants are required to validate and better understand the relationship between LSES and the incidence of COPD in the general population.

\section{Conclusions}

Lower household income and education status were more frequently found in subjects developing COPD among the general population. Among the components of SES, lower educational level was independently associated with the incidence of COPD. The findings of our study suggest that SES, especially low educational level, should be considered as a risk factor for COPD in the general population and implementation of preventive strategies for COPD in those with low educational status could be beneficial.

\section{Abbreviations}

COPD, chronic obstructive pulmonary disease; SES, socioeconomic status; LSES, low socioeconomic status; KoGES, Korean Genome and Epidemiology Study; PFT, pulmonary function test; FEV1, forced expiratory volume in 1 second; FVC, forced vital capacity.

\section{Author Contributions}

All authors contributed to data analysis, drafting or revising the article, have agreed on the journal to which the article will be submitted, gave final approval of the version to be published, and agree to be accountable for all aspects of the work.

\section{Funding}

This research was supported by a Korea University Ansan Hospital Grant. 


\section{Disclosure}

The authors report no conflicts of interest for this work.

\section{References}

1. Krieger N, Williams DR, Moss NE. Measuring social class in US public health research: concepts, methodologies, and guidelines. Annu Rev Public Health. 1997;18:341-378. doi:10.1146/annurev.publhealth.18.1.341

2. Ebner PJ, Ding L, Kim AW, et al. The effect of socioeconomic status on treatment and mortality in non-small cell lung cancer patients. Ann Thorac Surg. 2020;109(1):225-232. doi:10.1016/j.athoracsur.2019.07.017

3. Ellison-Loschmann L, Sunyer J, Plana E, et al. Socioeconomic status, asthma and chronic bronchitis in a large community-based study. Eur Respir J. 2007;29(5):897-905. doi:10.1183/09031936.00101606

4. Schechter MS, Shelton BJ, Margolis PA, Fitzsimmons SC. The association of socioeconomic status with outcomes in cystic fibrosis patients in the United States. Am J Respir Crit Care Med. 2001;163 (6):1331-1337. doi:10.1164/ajrccm.163.6.9912100

5. Rabin DL, Richardson MS, Stein SR, Yeager Jr H. Sarcoidosis severity and socioeconomic status. Eur Respir J. 2001;18 (3):499-506. doi:10.1183/09031936.01.00056201

6. Bakker JP, O'Keeffe KM, Neill AM, Campbell AJ. Ethnic disparities in CPAP adherence in New Zealand: effects of socioeconomic status, health literacy and self-efficacy. Sleep. 2011;34(11):1595-1603. doi:10.5665/sleep. 1404

7. Prescott E, Vestbo J. Socioeconomic status and chronic obstructive pulmonary disease. Thorax. 1999;54(8):737-741. doi:10.1136/ thx.54.8.737

8. Prescott E, Lange P, Vestbo J. Socioeconomic status, lung function and admission to hospital for COPD: results from the Copenhagen City Heart Study. Eur Respir J. 1999;13(5):1109-1114. doi:10.1034/ j.1399-3003.1999.13e28.x

9. Hegewald MJ, Crapo RO. Socioeconomic status and lung function. Chest. 2007;132(5):1608-1614. doi:10.1378/chest.07-1405

10. Cho KH, Nam CM, Lee EJ, et al. Effects of individual and neighborhood socioeconomic status on the risk of all-cause mortality in chronic obstructive pulmonary disease: a nationwide populationbased cohort study, 2002-2013. Respir Med. 2016;114:9-17. doi:10.1016/j.rmed.2016.03.003

11. Basagaña X, Sunyer J, Kogevinas M, et al. Socioeconomic status and asthma prevalence in young adults: the European community respiratory health survey. Am J Epidemiol. 2004;160(2):178-188. doi:10.1093/aje/kwh186

12. Johannessen A, Eagan TM, Omenaas ER, Bakke PS, Gulsvik A. Socioeconomic risk factors for lung function decline in a general population. Eur Respir J. 2010;36(3):480-487. doi:10.1183/ 09031936.00186509

13. Pauwels RA, Rabe KF. Burden and clinical features of chronic obstructive pulmonary disease (COPD). Lancet. 2004;364 (9434):613-620. doi:10.1016/s0140-6736(04)16855-4

14. Viegi G, Pistelli F, Sherrill DL, Maio S, Baldacci S, Carrozzi L. Definition, epidemiology and natural history of COPD. Eur Respir J. 2007;30(5):993-1013. doi:10.1183/09031936.00082507

15. Vogelmeier CF, Criner GJ, Martinez FJ, et al. Global strategy for the diagnosis, management, and prevention of chronic obstructive lung disease 2017 report. GOLD executive summary. Am J Respir Crit Care Med. 2017;195(5):557-582. doi:10.1164/rccm.201701-0218PP

16. Wijnhoven HA, Kriegsman DM, Hesselink AE, Penninx BW, de Haan M. Determinants of different dimensions of disease severity in asthma and COPD: pulmonary function and health-related quality of life. Chest. 2001;119(4):1034-1042. doi:10.1378/chest.119.4.1034

17. Hesselink AE, van der Windt DAWM, Penninx BWJH, et al. What predicts change in pulmonary function and quality of life in asthma or COPD? J Asthma. 2006;43(7):513-519. doi:10.1080/ 02770900600856954
18. Miravitlles M, Soriano JB, García-Río F, et al. Prevalence of COPD in Spain: impact of undiagnosed COPD on quality of life and daily life activities. Thorax. 2009;64(10):863-868. doi:10.1136/ thx.2009.115725

19. Celli BR. The importance of spirometry in COPD and asthma: effect on approach to management. Chest. 2000;117(2):15S-19S. doi:10.1378/chest.117.2_suppl.15s

20. Krieger N. A glossary for social epidemiology. $J$ Epidemiol Community Health. 2001;55(10):693-700. doi:10.1136/ jech.55.10.693

21. Cohen BH, Ball WC, Brashears S, et al. Risk factors in chronic obstructive pulmonary disease (COPD). Am J Epidemiol. 1977;105 (3):223-232. doi:10.1093/oxfordjournals.aje.a112378

22. Viegi G, Scognamiglio A, Baldacci S, Pistelli F, Carrozzi L. Epidemiology of chronic obstructive pulmonary disease (COPD). Respiration. 2001;68(1):4-19. doi:10.1159/000050456

23. Eisner MD, Blanc PD, Omachi TA, et al. Socioeconomic status, race and COPD health outcomes. J Epidemiol Community Health. 2011;65(1):26-34. doi:10.1136/jech.2009.089722

24. Yin P, Zhang M, Li Y, Jiang Y, Zhao W. Prevalence of COPD and its association with socioeconomic status in China: findings from China chronic disease risk factor surveillance 2007. BMC Public Health. 2011;11:586. doi:10.1186/1471-2458-11-586

25. Grigsby M, Siddharthan T, Chowdhury MA, et al. Socioeconomic status and COPD among low- and middle-income countries. Int J Chron Obstruct Pulmon Dis. 2016;11:2497-2507. doi:10.2147/ copd.S111145

26. Kanervisto M, Vasankari T, Laitinen T, Heliövaara M, Jousilahti P, Saarelainen S. Low socioeconomic status is associated with chronic obstructive airway diseases. Respir Med. 2011;105(8):1140-1146. doi:10.1016/j.rmed.2011.03.008

27. Kim Y, Han BG. Cohort profile: the Korean genome and epidemiology study (KoGES) consortium. Int J Epidemiol. 2017;46(2):e20. doi:10.1093/ije/dyv316

28. Shin C, Abbott RD, Lee H, Kim J, Kimm K. Prevalence and correlates of orthostatic hypotension in middle-aged men and women in Korea: the Korean Health and Genome Study. J Hum Hypertens. 2004;18(10):717-723. doi:10.1038/sj.jhh.1001732

29. Kim CY, Park Y, Leem AY, et al. Relationship between airway obstruction and incidence of metabolic syndrome in Korea: a community-based cohort study. Int J Chron Obstruct Pulmon Dis. 2018;13:2057-2063. doi:10.2147/copd.S157453

30. American Thoracic Society. Standardization of spirometry, 1994 update. Am J Respir Crit Care Med. 1995;152(3):1107-1136. doi:10.1164/ajrccm.152.3.7663792

31. Raju S, Keet CA, Paulin LM, et al. Rural residence and poverty are independent risk factors for chronic obstructive pulmonary disease in the United States. Am J Respir Crit Care Med. 2019;199(8):961-969. doi: $10.1164 / \mathrm{rccm} .201807-13740 \mathrm{OC}$

32. Gershon AS, Dolmage TE, Stephenson A, Jackson B. Chronic obstructive pulmonary disease and socioeconomic status: a systematic review. COPD. 2012;9(3):216-226. doi:10.3109/ 15412555.2011.648030

33. Tjepkema M, Wilkins R, Long A. Cause-specific mortality by education in Canada: a 16-year follow-up study. Health Rep. 2012;23 (3):23-32.

34. Akinbami LJ, Liu X. Chronic obstructive pulmonary disease among adults aged 18 and over in the United States, 1998-2009. NCHS Data Brief. 2011;(63):1-8.

35. Chen Y, Breithaupt K, Muhajarine N. Occurrence of chronic obstructive pulmonary disease among Canadians and sex-related risk factors. $J$ Clin Epidemiol. 2000;53(7):755-761. doi:10.1016/s0895-4356(99) 00211-5

36. Sahni S, Talwar A, Khanijo S, Talwar A. Socioeconomic status and its relationship to chronic respiratory disease. Adv Respir Med. 2017;85(2):97-108. doi:10.5603/arm.2017.0016 
37. Liberatos P, Link BG, Kelsey JL. The measurement of social class in epidemiology. Epidemiol Rev. 1988;10:87-121. doi:10.1093/oxfordjournals.epirev.a036030

38. Celli BR, MacNee W, Agusti A. Standards for the diagnosis and treatment of patients with COPD: a summary of the ATS/ERS position paper. Eur Respir J. 2004;23(6):932-946. doi:10.1183/ 09031936.04.00014304

39. Pierson DJ. Clinical practice guidelines for chronic obstructive pulmonary disease: a review and comparison of current resources. Respir Care. 2006;51(3):277-288.

40. Sarkar C, Zhang B, Ni M, et al. Environmental correlates of chronic obstructive pulmonary disease in 96779 participants from the UK Biobank: a cross-sectional, observational study. Lancet Planet Health. 2019;3(11):e478-e490. doi:10.1016/s2542-5196(19)30214-1
41. De Matteis S, Jarvis D, Darnton A, et al. The occupations at increased risk of COPD: analysis of lifetime job-histories in the population-based UK biobank cohort. Eur Respir J. 2019;54 (1):1900186. doi:10.1183/13993003.00186-2019

42. Sanderson E, Davey Smith G, Bowden J, Munafò MR. Mendelian randomisation analysis of the effect of educational attainment and cognitive ability on smoking behaviour. Nat Commun. 2019;10 (1):2949. doi:10.1038/s41467-019-10679-y

\section{Publish your work in this journal}

The International Journal of COPD is an international, peer-reviewed journal of therapeutics and pharmacology focusing on concise rapid reporting of clinical studies and reviews in COPD. Special focus is given to the pathophysiological processes underlying the disease, intervention programs, patient focused education, and self management protocols. This journal is indexed on PubMed Central, MedLine and CAS. The manuscript management system is completely online and includes a very quick and fair peer-review system, which is all easy to use. Visit http://www.dovepress.com/testimonials.php to read real quotes from published authors. 